\title{
LAS BARRAS BRAVAS. UN ACERCAMIENTO SOCIOLÓGICO A UN FENÓMENO URBANO
}

\author{
"BARRAS BRAVAS" (HOOLIGANS). A SOCIOLOGICAL APPROXIMATION TO AN \\ URBAN PHENOMENON
}

Germán Eliecer Gómez Eslava

Resumen

El fenómeno de las Barras Bravas en Bogotá ha adquirido especial importancia desde finales de la década de los noventa, en la medida en que se ha posicionado debido a los hechos violentos causados por choques entre los integrantes de estas agrupaciones en la ciudad. Sus orígenes se remontan a la década de los noventa y en poco tiempo han logrado crecer en número de integrantes hasta llenar las tribunas populares del estadio El Campín. Las situaciones asociadas a la violencia que estas barras protagonizan responden a la yuxtaposición de diversos factores tales como el odio que los integrantes de otra barra despiertan en los de la antagonista, consumos de sustancias alcohólicas y psicoactivas, la procedencia social de los integrantes de la misma, así como la frustración que inmensas capas de jóvenes sufren a diario en sociedades como la colombiana, y que en estos espacios encuentran la posibilidad de suavizar a través de la explosión emotiva que en algunas ocasiones desemboca en violencia. Este ejercicio toma como soporte la investigación realizada en el año 2001, pionera para la época, sobre el fenómeno de las barras en Bogotá y Colombia.

Palabras clave: barras bravas, identidad, jóvenes, violencia física, violencia simbólica.

Abstract

The hooligans (Barras bravas) phenomenon in Bogota has gained special significance since the late 90 's, whereas it's been positioned as a result of the violent clashes between members of these kind of fanbases in the city. Their origins trace back to the nineties and in a very short time they have managed to grow in members and fill the popular stands in "El Campín" Stadium. The situations associated to violence where the fanbase is involved result from juxtaposing factors such as the hatred that the members of the antagonist fanbase cause on their opposites, the use of alcohol and psychoactive drugs, the social origins of their members, as well as the frustration that young people suffer in societies like the Colombian, who find in these spaces a possibility to lighten through the emotional explosion that sometimes end up in violence. This exercise is supported on the research conducted in 2001 about the hoooligans phenomenon in Bogota and Colombia, a pioneer for its moment.

Keywords: Barras Bravas (hooligans), identity, youngsters, physical violence, symbolic violence.

Fecha de recepción: 8 de julio de 2011

Fecha de aprobación: 18 de octubre de 2011

1 Sociólogo egresado de la Universidad Nacional. Magister en Comunicación de la Pontificia Universidad Javeriana. Miembro Fundador e investigador de la Asociación Colombiana de Estudios Sociales del Deporte ASCIENDE. Correo electrónico: gomezeslava@gmail.com; gomezeslava@yahoo.com 


\section{Introducción}

En el año 2001 finalizó la investigación titulada "la Violencia en el Fútbol vistas a través del Fenómeno de las Barras Bravas" (Gómez, 2001). El tema abordado para la época de la investigación suscitó una serie de suspicacias academicistas, dado que para algunos académicos dicho tema carecía de relevancia sociológica. Los acontecimientos acaecidos en las dos últimas décadas entorno a este fenómeno requieren que la sociología ubique sobre él su mirada, para contribuir en las explicaciones necesarias para abordarlo de manera adecuada.

La investigación tomó como punto de partida la necesidad de describir el fenómeno, para lo cual se aplicaron a 1063 barristas encuestas que buscaban caracterizar de manera general a los integrantes de estas agrupaciones. Las barras con las cuales se trabajo fueron las siguientes:

1. Comandos Azules No 13.

2. Guardia Albiroja Sur.

3. Disturbio Rojo.

4. Los del Sur.

Se aplicaron, además, 20 entrevistas a profundidad con líderes de estas barras, autoridades de policía, representantes de la alcaldía, periodistas deportivos e integrantes de equipos de fútbol de Bogotá.

La revisión bibliografía realizada en el año 2001 evidenció la casi inexistente investigación que desde las ciencias sociales se ha realizado respecto a este fenómeno. En la investigación realizada por A, Villanueva \& A, Amaya (2010), se referencian aproximadamente cinco investigaciones para el año 2000 sobre el fenómeno de las Barras Bravas, que abordan el tema desde la perspectiva de la comunicación social y el periodismo. Por lo demás, la producción académica sobre dicho fenómeno era mínima. No obstante, los estudios sociales en el cono sur, presentaban una vasta producción de investigaciones y estudios de caso sobre el particular, hecho que sirvió de soporte para configurar la investigación propia. Actualmente, y tomando como referencia la investigación ya citada de A, Villanueva \& A, Amaya (2010), se han realizado aproximadamente 37 investigaciones sobre el fenómeno.

Por último, desde la investigación se construyó una categoría empírica de la barra, que se amparó en conceptos sociológicos tales como Masa y Comunidad, a partir de los trabajos desarrollados por M, Weber (2006) y E, Canetti (1997). Esta categoría comprende todas las estructuras que determinan el fenómeno de estudio, algunas de las cuales se hacen conscientes para los mismos integrantes (por ejemplo, el concepto de identidad), mientras otras permanecen ocultas, como el poder y la dominación entre otros. Sobre esta base se explica la adopción del concepto de Barra Brava como instrumento de homogenización de las diversas prácticas desarrolladas por estos individuos para dar una adecuada explicación sociológica a este fenómeno.

Para este texto desarrollaremos la siguiente estructura:

- Descripción de la Barra.

- La violencia en las Barras.

- Conclusiones.

Empezaremos por la descripción de las barras como fenómeno sociológico.

\section{Descripción de la Barra}

Para este artículo, definiremos las Barras como asociaciones de individuos determinados por la pasión y gusto por el fútbol que asumen la forma de comunidades de tipo emotivo. En Weber (2006) el concepto de comunidad es definido como "Una relación social en la medida en que la acción social esté basada en el sentimiento subjetivo de pertenencia en común por parte de los participantes (sentimiento de Índole afectiva o tradicional)" (P.134).

Se componen en su gran mayoría (96\%) por jóvenes entre los 14 y los 26 años de edad, que asisten periódicamente al estadio a apoyar al equipo de sus preferencias. En A, Villanueva \& A, Amaya (2010), este porcentaje disminuye a aproximadamente el 70 \% (p.39). Esta situación se explica, por una parte, en la ampliación del rango de edad para acceder a la Barra; es decir, ingresan adolescentes cada vez menores. Por otro lado, este fenómeno también tiene su origen en el mantenimiento de grupos "Vieja Guardia" que ya exceden los 30 años. N, Rodríguez Melendro (2010) ubica igualmente la participación de los barristas en el rango de edad comprendido entre los 14 y los 30 años, con especial participación de los 20 a los 25 años (P.101).

Los barristas se ubican en las graderías populares, que han sido definidas como los extremos y que, para el caso especifico del estadio el Campín, se encuentran ubicadas en los sectores norte y sur, respectivamente. Por lo general, la óptica en estas graderías es considerablemente inferior, ya que la visual del campo de fútbol se determina por la ubicación en este lugar del estadio, donde se observa adecuadamente la mitad del terreno de juego más cercana a la tribuna. Así, queda 
para la visual la otra mitad al otro extremo y se dificulta por tanto apreciar en detalle lo que ocurre, a diferencia de otras tribunas del estadio, como la occidental, donde la óptica es equidistante entre las dos porterías. Sobre esta situación influye la disposición de las cámaras para las trasmisiones de televisión, que se ubican precisamente sobre el costado occidental, lo que convierte tanto a este costado como al oriental en las tribunas privilegiadas para la observación del espectáculo.

A su vez, en el disfrute del espectáculo, caracterizado por altas descargas emotivas, acompañadas de pólvora, bengalas, extintores, tiras de papel y sal de nitro, encontramos otra diferencia entre estas barras, que las hacen particularmente deferentes con respecto a los hinchas tradicionales que presentan en sus prácticas cierta pasividad en el disfrute del espectáculo. N, Rodríguez Melendro (2010) incorpora algunas referencias referidas a la forma en la cual los hinchas de antaño asistían al estadio en sana armonía y donde la violencia no tenía cabida. Rodríguez postula una crítica a esta postura al manifestar que las expresiones de agresividad y violencia no eran ajenas a estos espectáculos (P. 75- 85). Ahora bien, el fenómeno urbano de la Barras presenta considerables diferencias de tipo cualitativo que sí permiten ubicarlo como novedoso en relación con las expresiones de antaño. La incorporación de la violencia como una pauta de reafirmación de la identidad en torno al concepto de aguante definen cualitativamente las prácticas que caracterizan a los hinchas contemporáneos. Al respecto, Garriga plantea en un artículo citado por P, Alabarces (2006) la necesidad de abordar la violencia como un fenómeno de estudio en aras de aportar a la investigación social:

Las interpretaciones que conciben la violencia como una acción irracional propia de un estado de incivilización evitan ahondar en las representaciones sociales de estas acciones y, por esta razón, no aprehenden los vínculos con otras prácticas. La tarea de los investigadores sociales es descubrir aquellos significados que parecen incoherentes y arbitrarios, relevando el trasfondo de coherencia que existe en el comportamiento de los agentes. (p. 39)

La descripción continúa incorporando prácticas como la conformación de colectivos organizados que se manifiestan en la formalización de reuniones en espacios y tiempos distintos a los del evento deportivo. Dentro de las dinámicas propias de estas barras, hacer extensivo el tiempo dedicado a las acciones propias referidas al apoyo del equipo y la organización de la barra, como la programación de viajes, la realización de banderas, escudos, pintas o graffitis y la adecuación de canciones o cánticos, acciones que involucran trascender el tiempo que en otros sectores, a lo sumo involucra el del día de realización. Su organización interna igualmente responde a lógicas jerárquicas legitimadas por el consenso del colectivo, dentro de las cuales se utilizan los siguientes elementos:

1. Antigüedad.

2. Aguante.

3. Carisma.

La denominación de aguante supone el ejercicio de resistir los embates del juego, los ataques de otras barras, tanto como la capacidad para el canto y la pelea. La organización interna de la Barra se da a través de estructuras de poder verticales y jerárquicas, que se legitiman por los elementos antes mencionados. El tiempo de pertenencia a la barra, la disposición y habilidad en los enfrentamientos tanto internos como externos, así como la ascendencia sobre los seguidores, son fundamentales, y complementarios. Esta organización adopta esquemas externos propios de otro tipo de agrupaciones, como las culturas juveniles asociadas a la música y que terminan confluyendo dentro y fuera del estadio en torno a la barra.

Las Barras también realizan acciones para acompañar sus prácticas dentro del estadio, referidas a la incorporación de emblemas propios de sus equipos, como banderas de grandes magnitudes. Dichas acciones suponen acuerdos racionales prácticos al interior de la barra, lo que caracteriza el fenómeno como algo totalmente distinto a los movimientos espontáneos que en ocasiones se gestan en torno al fútbol. La adopción de himnos y cánticos adaptados a las particularidades de sus equipos y que son interpretados antes, durante y después del encuentro deportivo, definen otro aspecto de distinción de estas barras y ratifican lo planteado anteriormente. Por lo general, las líricas de sus cantos presentan niveles altos de agresividad que promulgan la eliminación del contrario.

Las Barras apropian la ciudad a través del establecimiento de territorios simbólicos, para lo cual crean códigos de interpretación propia, manipulando y adecuando el lenguaje en función de esta práctica de apropiación, que plasman en las paredes de la ciudad a través de los graffitis.

\section{La identidad en juego}

La participación de estos jóvenes dentro de las barras bravas responde en últimas a las necesidades subjetivas de generar procesos de identidad que dentro de las sociedades contemporáneas el Estado, la Nación, la Fa- 
milia y la Iglesia, no logran copar en su totalidad. Son procesos de construcción identitaria móviles y fluidos, determinados por la lógica y la dinámica propia de estas agrupaciones, así como por los procesos de globalización, en contraposición a los procesos identitarios desarrollados desde la Familia, el Estado, la Nación, que podrían definirse como estáticos y sólidos.

La identidad entra en juego en el momento en que el actor se asume como perteneciente a un colectivo especifico, en contraposición a un otro diferente y antagónico que garantiza la cohesión del grupo originario. En las Barras Bravas estos procesos se materializan en las prácticas que, como colectivos, implementan y buscan la negación de las otras Barras Bravas, e incluso de subgrupos pertenecientes a la misma Barra, como el sonado caso del conflicto entre Comandos y Blue Rain, ambos grupos seguidores del equipo los Millonarios.

La implementación de emblemas y símbolos, así como la creación de páginas de Internet de sus barras como resultado de su apropiación al colectivo, evidencian la manera operativa como ellos hacen de la identidad un elemento determinante, que utiliza en alto grado el espectro de la vida cotidiana en función de la pertenencia a la Barra.

\section{La violencia en las barras}

Para esta investigación, la violencia se define desde dos perspectivas igualmente significativas: física $\mathrm{y}$ simbólica. La violencia se plasma como un factor integrador del grupo en la medida en que se incorporan a ella procesos de racionalización, que los congregan hacia objetivos específicos tendientes a posicionar la barra dentro del espacio social particular donde se desarrolla. estos procesos se definen específicamente como el triunfo sobre las otras barras, en busca del reconocimiento como la más grande y la mejor.

La violencia se soporta en los fuertes lazos de solidaridad que rigen como principio moral del Barrista, refe-

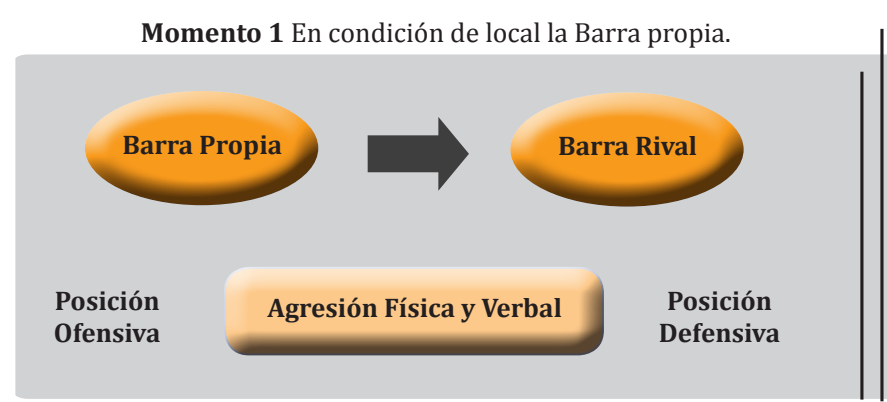

ridos a la defensa de su barra y sus integrantes como premisa fundamental de acción. Esta práctica subyace a la lógica de la defensa y el ataque a los oponentes. Lo explicaremos según diversos momentos de acuerdo a los gráficos siguientes:

Las graficas presentadas pretenden describir de manera general los comportamientos violentos en términos de apropiación territorial. El principio es el mismo: Ataque y defensa. No obstante lo que se observa en el momento 2, se incorpora como motor de acción el elemento venganza, que determina fuertemente el tema de la violencia, lo que genera un circulo ad infinitum en enfrentamientos entre estas agrupaciones. Al respecto, Garriga (2006) incorpora el concepto de la violencia desde su práctica como la tercera cualidad de las hinchadas:

Los miembros de la hinchada, según ellos mismos, ponen a disposición del honor del club sus posibilidades violentas para no ser ofendidos por las parciales adversarias. Es decir, que los pibes consideran que subyacente al encuentro futbolístico se dirimen cuestiones de honor y prestigio del club y de sus simpatizantes que solo pueden debatirse en el plano de la violencia. (p.41)

Entraremos a explicar la forma que la violencia toma, ya sea física o simbólica.

La violencia física. Se define como todas las acciones realizadas con la clara intención de eliminar o generar daño físico al enemigo. Para el caso de las Barras Bravas, estos comportamientos se centran en los integrantes de las barras contrarias, la policía, los equipos contrarios y los árbitros. La violencia protagonizada por las barras bravas se caracteriza por desarrollarse no solo en el transcurso del tiempo efectivo (partido de fútbol), sino también en el tiempo anterior y posterior al encuentro. Es una violencia premeditada, racionalmente planeada; se llega con la clara intención de agredir al contrario, no como producto de la espontaneidad propia de factores asociados al encuentro de fútbol, sino como parte de una dinámica interiorizada dentro del grupo.
Momento 2 En condición de local la Barra Rival.

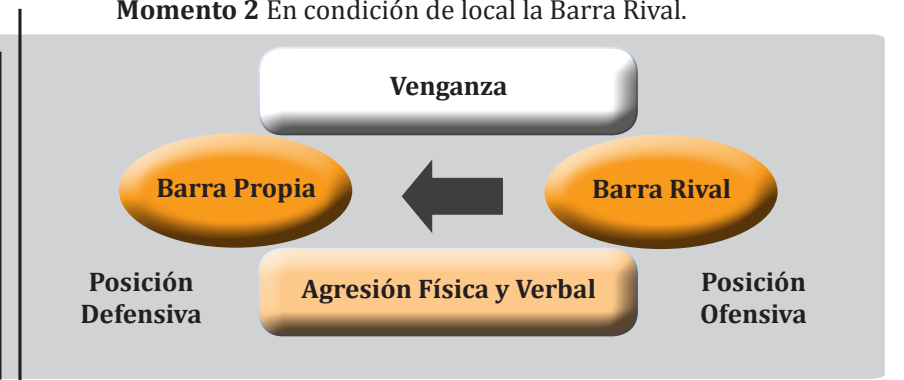


Las Barras han incorporado prácticas sustentadas en el robo de emblemas significativos de las otras barras (Banderas, camisetas, entre otras) o de la policía, que son definidos como trofeos y que materializan los triunfos de estas barras. Esto es un componente importante en las dinámicas del reforzamiento de la identidad hacia el grupo.

La violencia Simbólica. Para este trabajo, se entiende como la utilización del lenguaje verbal y escrito, signos y símbolos, que pretenden agredir o eliminar simbólicamente al adversario. Se encuentra en las líricas de los cantos, en las pintas o graffitis que realizan en la calle, en la dinámica de Internet (páginas web, chat y salas temáticas), en las banderas y escudos, y busca la negación del adversario. Así mismo, la comparación del adversario con símbolos que son valorados negativamente dentro de la sociedad materializa esta dinámica, que busca congregar a los participantes en torno a estas prácticas mediante ataques simbólicos, enfocándose nuevamente en un adversario o enemigo común, que ratifica la cohesión existente dentro de la barra.

Esta violencia simbólica por lo general precede a la violencia física. Su espacio de mayor difusión es la Internet y las paredes de las calles, donde se materializa la guerra de Graffitis. Como indicábamos anteriormente, se han modificado algunos elementos gramaticales del idioma, con el fin de hacer consenso frente a estas acciones. Por ejemplo, la mayoría de estas barras realiza graffitis de demarcación territorial apelando a las iniciales o abreviaturas de los nombres de sus barras. Para el caso de comandos Azules, se asocian a las iniciales C.A.; en el caso del Disturbio Rojo, es D.R. Los del Sur, L.D.S. y la Guardia Albirroja es GARS. En la guerra de graffitis, a esta ultima abreviatura, le adicionan "as", para significar Garzas", conocidas aves de patas y picos largos, sin importar que estas últimas se escriben con " $z$ ". Es parte de los acuerdos que como comunidad han incorporado y que para estos son válidos, dado lo que importa es lo que significa, no cómo se escribe.

\section{¿Por qué tan bravas?}

El contexto propio de la contienda futbolera, sustentado en la competencia entre bandos contrarios, permite que dicha dinámica se reproduzca velozmente en las tribunas, lo cual es una condición detonante para los brotes agresivos y violentos en los estadios. Esta situación no es exclusiva de los barristas; también involucra a los hinchas y los mismos espectadores.

En lo pertinente a la violencia presentada por las barras bravas se asumen prácticas y dinámicas desarrolladas en los contextos, tanto suramericanos como europeos, referidos a los enfrentamientos violentos con otros subgrupos. Los factores que contribuyen a la violencia están asociados a procesos de exclusión social, cultural y política a las que se ven sometidos los jóvenes urbanos, que ven en estos espacios la oportunidad de descargar sus rencores producto de estas realidades (la Frustración). Según la Personería de Bogotá (2011), el $60 \%$ de 272 jóvenes entrevistados no tiene trabajo, el $25 \%$ no cuenta con servicios de salud y el $63 \%$ se sienten discriminados. Por tanto, se presenta un efecto catalizador y de catarsis en estos colectivos, lo que presenta líneas de fuga frente a las situaciones cotidianas que se presentan como condición del ser joven urbano.

Las dinámicas fuertemente emotivas desarrolladas por las Barras Bravas tanto dentro como fuera del estadio hacen que desde la sociedad en general se perciban como subgrupos de naturaleza violenta. Ésto ha dado como resultado una estigmatización generalizada dentro de la sociedad, pues se juzga de manera enteramente negativa las prácticas de estos jóvenes, sin diferenciar si son o node carácter violento.

El consumo de alcohol y sustancias psicoactivas es detonante de los comportamientos violentos. Además, el carácter anónimo que las grandes masas le otorgan al individuo permite que se relajen los sistemas de comportamiento y regulación de la violencia.

La presentación que desde los medios masivos de comunicación se hace de los eventos violentos y que hace énfasis en la graficación exclusiva del hecho, contribuye a reproducir las percepciones generalizadas que desde la sociedad en general se tiene sobre este fenómeno.

\section{El fenómeno massmediatico}

La relación que se construye entre barras bravas y medios masivos de comunicación toma como punto vinculante el factor violencia. Las Barras Bravas buscan reconocimiento en los medios, al tiempo que los medios buscan audiencia en las Barras.

El abordaje del fenómeno por parte de los medios masivos de comunicación se da desde la inmediatez que los formatos noticiosos televisivos exigen. El abordaje del fenómeno en la radio adquiere mayor profundidad en la medida en que se permite, dada la relativa flexibilidad frente al formato televisivo, extender el tiempo destinado al tratamiento del mismo. No obstante los niveles de análisis y de presentación de este fenómeno, los medios no logran trascender los límites de la moralidad enquistada dentro de los contextos sociales donde se desarrollan. Por tanto, estas "explicaciones" 
solo contribuyen a seguir estigmatizando el fenómeno, pues se agotan en denuncias moralistas proclives a la exigencia de medidas enteramente punitivas, que se quedan cortas ante la complejidad del fenómeno al reducirlo a acciones desarticuladas de vandalismo o delincuencia.

La reproducción de lugares comunes, como definir a los integrantes de las barras como drogadictos, hampones y delincuentes, genera barreras simbólicas que radicalizan el problema, imposibilitando de entrada cualquier tipo de estrategia tendiente a canalizar las dinámicas propias de estos colectivos y a disminuir los hechos esporádicos de violencia.

En el seguimiento explícito de los enfrentamientos entre las barras, realizado especialmente por la televisión, es recurrente el uso de los medios interactivos y mediáticos que permiten, por ejemplo, detener las imágenes en los momentos donde se presenta las agresiones, acompañadas de ampliaciones sobre las tomas y los recuadros o círculos donde se encuadran los elementos por lo general corto punzantes con los cuales se atacan a los oponentes. Estas imágenes se han incorporado dentro de las estructuras narrativas del medio como elementos fundamentales y determinantes que en últimas buscan garantizar el un gran impacto en las audiencias frecuentes de estos noticieros. Cabría cuestionar los procesos mediante los cuales las audiencias reciben estas noticias y el proceso negociador de ellas frente a lo presentado.

\section{Conclusiones}

Por último, se sugiere tener presente el carácter multidimensional del fenómeno, pues en él confluyen distintas variables que determinan la dinámica propia de estas barras. Por tanto, es necesario superar la radicalización de los juicios valorativos, para enfocarse en una visión integral de la situación que trascienda los postulados que formulan la implementación de medidas netamente punitivas como la única salida y solución posible.

La ley 1445 de 2011 modifica la ley 181 de 1995 referida a la organización del deporte en Colombia. Esta ley incorpora bajo el título $\mathrm{V}$ las disposiciones en materia de seguridad y convivencia, presentando las distintas sanciones que recibirán las personas que ocasionen conductas que atenten contra el buen comportamiento dentro de los estadios. Esta ley, entre otras, incorpora sanciones a las agresiones verbales que se den dentro del Estadio, pero no define claramente lo que se considera como agresión verbal, lo que deja vacíos interpretativos complejos para la reglamentación de la misma. Consideramos que, a pesar de las buenas intenciones de tratar de regular los comportamientos violentos en los estadios, este tipo de leyes abordan de manera superficial la magnitud del fenómeno que, como se ha descrito en este texto, responde a lógicas estructurales propias de la sociedad colombiana y debe ser abordado de manera integral, para prevenir que se desplace hacia otros escenarios, como ya está ocurriendo en las distintas localidades de Bogotá.

Por tanto, proponemos garantizar la destinación de recursos que permitan desarrollar investigaciones sobre este tema, para lograr comprenderlo en su justa magnitud y en aras de garantizar la formulación de políticas públicas que contribuyan a integrar en vez de a segregar las dinámicas juveniles contemporáneas. Es menester realizar acuerdos y acciones conjuntas dentro de las instituciones públicas, para articular programas y proyectos que brinden alternativas concretas de realización de proyectos juveniles desde sus propias lógicas. Por último, se debe analizar el papel de la familia en el desarrollo de estos fenómenos, dado que como institución de socialización y formación está en una evidente crisis, que se puede traducir en oportunidad si se establecen puentes vinculantes entre los sectores educativos, culturales y estatales con la familia, para interactuar en la formación de los niños y jóvenes como sujetos determinantes de su entorno.

\section{Referencias}

Alabarces, P. (2006) Hinchadas. Buenos Aires: Prometeo Libros.

Canetti, E. (1997) Masa y Poder. Buenos Aires: Muchnik Editores de Idiomas Vivientes, S.A.

Garriga, José (2007). Haciendo amigos a las Piñas. Violencia y Redes Sociales de una Hinchada del Futbol. Prometeo Libros. Buenos Aires.

Gómez, G. (2001) La Violencia en el Futbol vista a través del fenómeno de las Barras Bravas. Tesis de grado para optar al título de Sociólogo, Facultad de Ciencias Humanas, Universidad Nacional de Colombia.

Personería de Bogotá (2011). Consultado el 6 de julio de 2011 en: http://www.personeriabogota.gov. co/?idcategoria $=4485$.

Rodríguez- Melendro, N. (2010) Futbol y Afición. Proceso en la manera de alentar a los equipos profesionales capitalinos (Santa Fe y Millonarios): La época del dorado y los años 80-90. Tesis para optar al título de Magister en Sociología. Facultad de Ciencias Humanas, Universidad Nacional de Colombia. Bogotá.

Villanueva, A. y Amaya, A. (2010) Los Hinchas de La Hinchada, Un Acercamiento Social, Cultural, Histórico y educativo a la Barra de Futbol Comandos Azules D.C. entre 2005 y 2009. Tesis de grado para optar al título de magíster en Educación. Facultad de Educación. Universidad Pedagógica Nacional. Bogotá.

Weber, M. (2006) Conceptos Sociol 